\section{Técnicas constructivas, comunidades locales y poderes feudales}

Margarita Fernández Mier

Universidad de León

\section{Resumen}

En este artículo se realiza un primer acercamiento a las técnicas constructivas presentes en una serie de valles del occidente de Asturias entre los siglos XI-XIII, relacionándolas con el nivel técnico de las comunidades aldeanas en las que se localizan las construcciones y con los poderes feudales que las financian. Esto ha permitido constatar un ambiente técnico muy similar en toda la zona, siendo en la mayoría de los casos obras ejecutadas con técnicas de albañil, restringiéndose los trabajos de cantería a elementos muy concretos dentro de las edificaciones.

Palabras clave: Técnicas constructivas, Asturias, Iglesias propias, Poderes feudales.

\begin{abstract}
This article makes a first approach to constructive techniques present in a series of valleys in the west of Asturias between the $11^{\text {th }}$ and $13^{\text {th }}$ century, relating them to the technical level of hill communities where the constructions are found and with the feudal powers that finance them. This has made it possible to prove the existence of a very similar technical environment throughout the area, as the majority of cases are works carried out with labourers' techniques, restricting stonemason work to very specific elements within the buildings.
\end{abstract}

Key words: Construction techniques, Asturias, local churches, Feudal powers.
El objetivo de este trabajo es mostrar las técnicas constructivas presentes en el alto valle del Narcea (Asturias) entre los siglos XI-XIII, relacionándolas con el nivel técnico de estas comunidades de montaña y con los poderes feudales que financian la arquitectura de prestigio. Para ello hemos analizado todas las construcciones religiosas de dicho valle en las cuales se documentan distintas técnicas constructivas que, en algunos casos, pueden ser adscribibles a períodos cronológicos determinados (fig. 1).

Como premisa básica hemos podido establecer una división entre diversos niveles constructivos que responden a ciclos productivos bien diferenciados. Ha sido necesario distinguir entre "técnicas de cantero", asociadas a la sillería, y las «técnicas de albañil», en la cual la mampostería irregular y concertada o "pequeño aparato» con variantes, muestran el predominio de esta figura profesional en la conducción y dirección de la obra. Esta división se refleja en el empleo de un instrumental y de procedimientos de extracción, elaboración y colocación del material bien diferentes. En la mampostería se precisa la mano de un albañil que se encarga de colocar los distintos tipos de piedra y, en algunos casos, de trabajar mínimamente las aristas para lograr unas buenas juntas; en el trabajo realizado por un maestro cantero se precisa de una serie de conocimientos técnicos y geométricos que le permitan realizar sillares homogéneos para levantar un muro. Esto trae consigo la posibilidad de distinguir distintas técnicas constructivas según éstas sean ejecutadas por obreros comunes o por maestros de obra y, por lo tanto, distintos ciclos productivos según las técnicas documentadas (Fernández Mier, Quirós Castillo, 1999: 372).

A su vez, estos grupos de técnicas constructivas reflejan contextos productivos y socioeconómicos muy distintos. Es oportuno llegar a analizar los criterios que determinan la función social de la arquitectura y el desarrollo de las fuerzas productivas, variables que interrelacionadas determinan el tipo de paramento empleado en cada período histórico, a la vez que permiten acercarse al proceso de feudalización del mundo alto medieval, ya que, detrás de estas construcciones se encuentran los poderes feudales en proceso de consolidación.

Las construcciones realizadas en Asturias durante la alta Edad Media, las iglesias prerrománicas, lo fueron con técnicas de albañil. No será hasta finales del siglo IX o principios del $\mathrm{X}$ — con la realización del pórtico Sur de Valdedios - cuando se produzca la sustitución de las técnicas de albañil por las de cantero con lo que eso supone de innovación técnológica. Sin embargo, las construcciones de cantería no se generalizarán, a pesar de que conservemos algunos interesantes ejemplos realizados con sillares del siglo XI, 


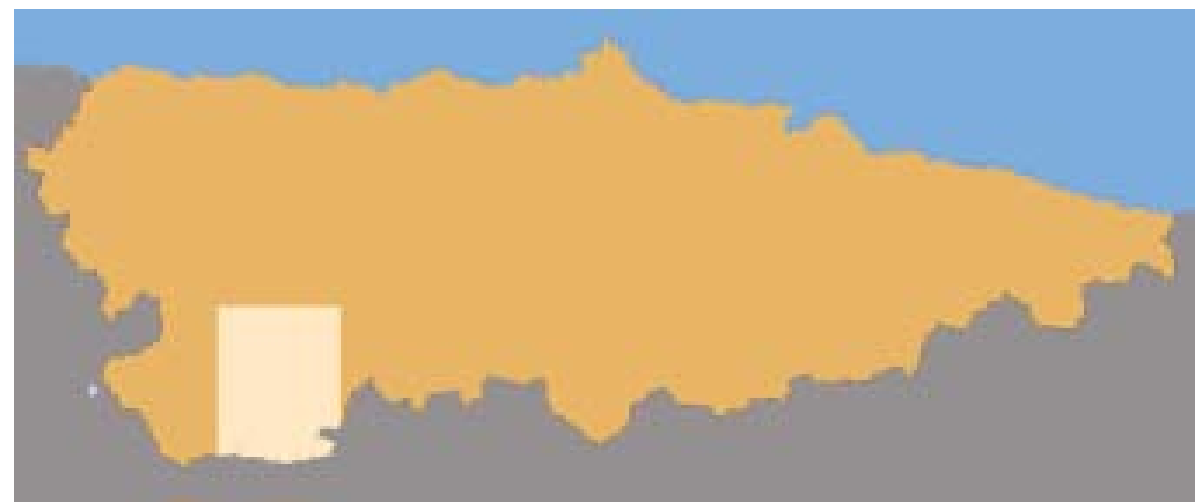

Fig. 1. Localización geográfica de la zona objeto de estudio

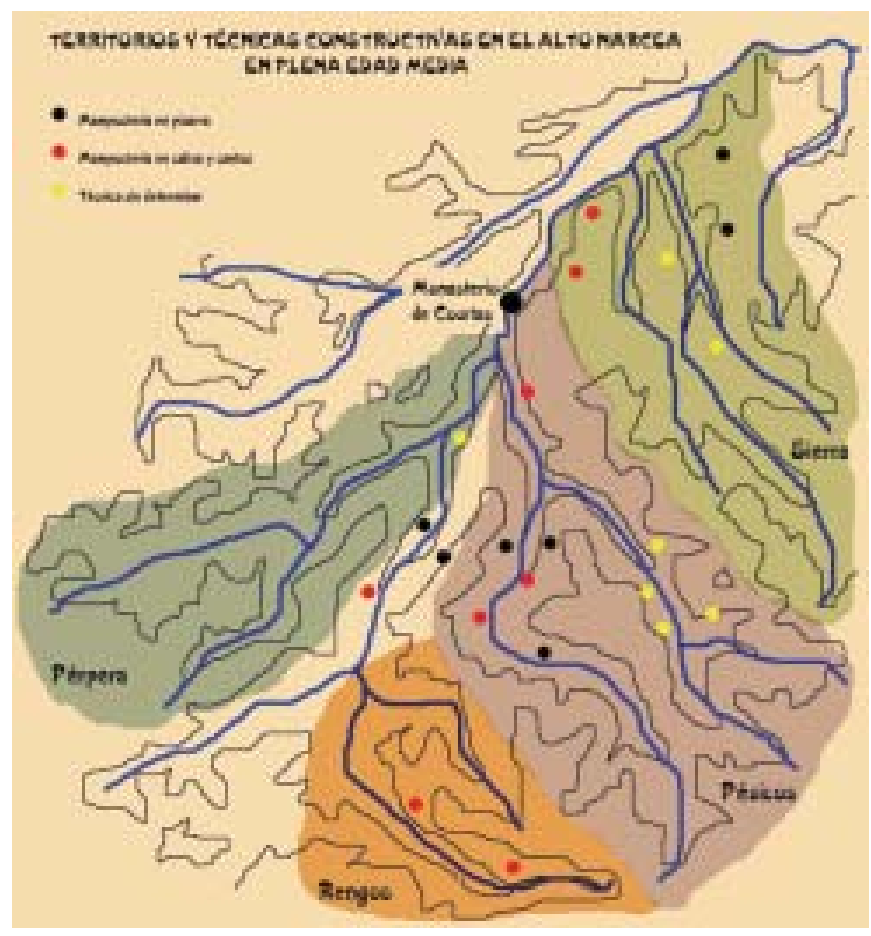

Fig. 2. El alto valle del Narcea está formado por varios subvalles de montaña que en Alta y Plena Edad Media constituían diversos territorios que estaban en manos de la misma aristocracia local que lleva a cabo la dotación de los monasterios en los siglos $x$ y xı. La fundación del monasterio de Courias por los condes Piniolo y Aldonza — cercanos a la monarquía astur-leonesa- en 1044 en la confluencia de varios de estos territorios, responde al intento de crear un centro de poder, del cual pasan a depender gran número de propiedades, que sirve de apoyo a la monarquía y que desestructura unos territorios que estarían en manos de una aristocracia local de la que apenas tenemos información. Así, a lo largo de los siglos XI y XII, el monasterio se convierte en el mayor poder feudal de la zona y pasan a depender de él las instituciones monásticas propias que se habían fundado en los siglos $\mathrm{x}$ y $\mathrm{xI}$ como ocurre con San Pedro de Teberga, sino que la utilización de las técnicas de cantería estará en relación con el nivel técnico local y con la capacidad económica de quien financia la construcción (FERnández Mier, Quirós Castillo, 1999: 375).

En el alto valle del Narcea (fig. 2) contamos con documentación escrita y con algunas lápidas de consagración que nos permiten constatar la existencia de diversas construcciones en el siglo XI. En éstas, desafortunadamente, nada permanece de la fábrica original pero, sin embargo, nos informan sobre la existencia de una aristocracia local que lleva a cabo diversas fundaciones eclesiásticas como monasterios propios — caso de los monasterios de San Salvador de Cibuchu y Santa María de Vil.lacibrán fundados por la familia de Alvaro Vermudez y Guina Gogniz o los de Santa María de Monasteriu d'Ermu y San Salvador de Berguñu fundados por Alfonso Roderici, también el monasterio de San Miguel de Bárzana, localizado en el territorio de Tinéu, cuya fundación data del siglo $\mathrm{X}-$. Se trata de pequeños monasterios que no siempre están servidos por una comunidad de monjes, que están ligados a la aristocracia emergente de la zona y que, además de funcionar como una célula económica receptora de rentas, bien por la explotación de su patrimonio o por el ejercicio de las funciones parroquiales del lugar en el que está emplazada, funcionan como patronos espirituales y temporales, lo que favorece el continuo incremento de su patrimonio y la aparición de relaciones de dependencia; proporcionan rentas y hombres de los que, en última instancia, se benefician sus patrones laicos (LORING GARCÍA, 1987: 95). Son una realidad ligada a los emergentes poderes feudales que en algunas ocasiones les sirve para introducirse en una comunidad. Estas iglesias propias después de su fundación se dividen progresivamente entre los herederos de los fundadores, para terminar pasando a depender del monasterio de Courias a lo largo de los siglos XI y XII.

Las fábricas de estos edificios - y de otros en el valle cuyos orígenes no tenemos documentados- responden a 


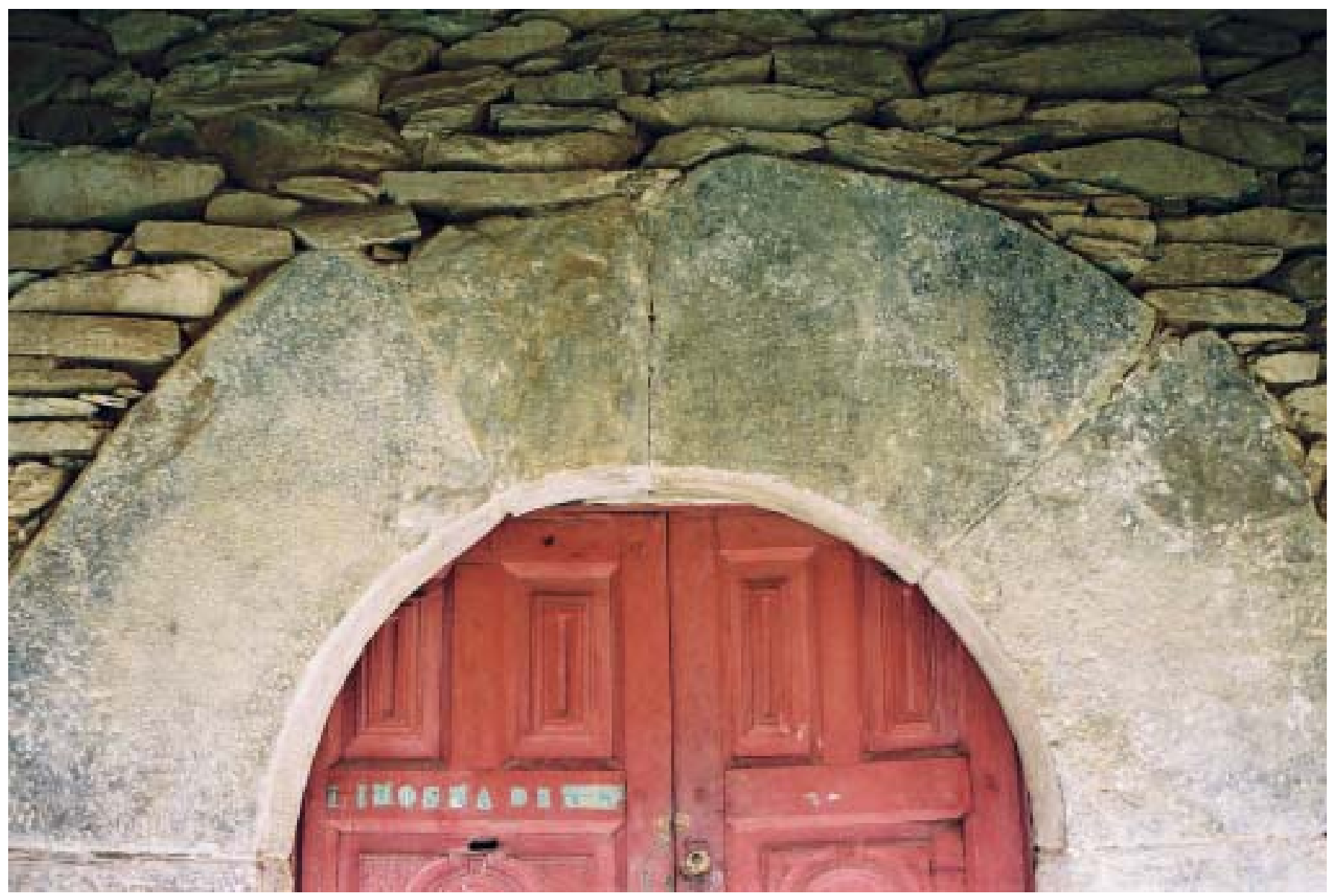

Fig. 3. Santa María de Castañéu, siglo xil. Paramento de mampostería enripiada por hiladas de caliza en la cual se procuran formar unas hiladas rústicas y se colocan las piedras tal y como llegan o ligeramente retocadas con martillo; los huecos se rellenan con ripio y esquirlas de piedras recubiertas de mortero por todos lados; apenas si se usan los cantos rodados. En los vanos de esta construcción aparecen los trabajos de cantería, tanto en la puerta lateral S. como en la puerta de ingreso por el O., presentando los mismos un acabado realizado con azuela y puntero

remodelaciones que los historiadores del arte fechan en los siglos XII y XIII y nada permanece de la primitiva fábrica de los siglos X y XI. Pero teniendo en cuenta el uso mayoritario de la mampostería en las actuaciones de los siglos XII y XIII, parece lícito pensar en la ausencia de trabajos de cantería en las obras del siglo XI, contrastando con otras construcciones realizadas completamente en sillares en el mismo período como San Pedro de Teberga. Esto puede ser un indicio del carácter local de la aristocracia que funda estos monasterios y financia las construcciones y de un escaso desarrollo de las fuerzas productivas que permita acometer actuaciones de mayor envergadura.

De las construcciones de los siglos posteriores, la técnica constructiva que podemos datar en el siglo XII es la presente en la iglesia de Santa María de Castañéu (fig. 3), consagrada en el año 1166 (Diego SANTOS, 1993: 151), habiendo estado colocada la lápida fundacional en el paramento Norte de la iglesia hasta hace poco tiempo y fechando, por lo tanto, la técnica constructiva. En este caso se tra- ta de un paramento de mampostería enripiada por hiladas de caliza y apareciendo en los vanos de la construcción los trabajos de cantería. A partir de la lápida de consagración de la iglesia podemos documentar la técnica constructiva existente en esta zona en el siglo XII, combinando los trabajos de mampostería y la cantería, haciéndose visible la presencia de maestros canteros que realizan los trabajos más elaborados, posiblemente en la propia cantera, y la presencia del albañil que lleva a cabo la realización del edificio en mampostería y utilizando los elementos de mayor precisión técnica realizados por el cantero, todo ello en edificios muy modestos con una única nave.

Si ésta es la técnica constructiva que podemos constatar en las construcciones del siglo XII, difiere poco de la técnica que se documenta en aquéllas atribuidas al siglo XIII, dentro de las cuales existen dos tipos principales de técnicas constructivas:

- Mampostería enripiada de hiladas de caliza, con los trabajos de cantería en los vanos — que hemos definido para 


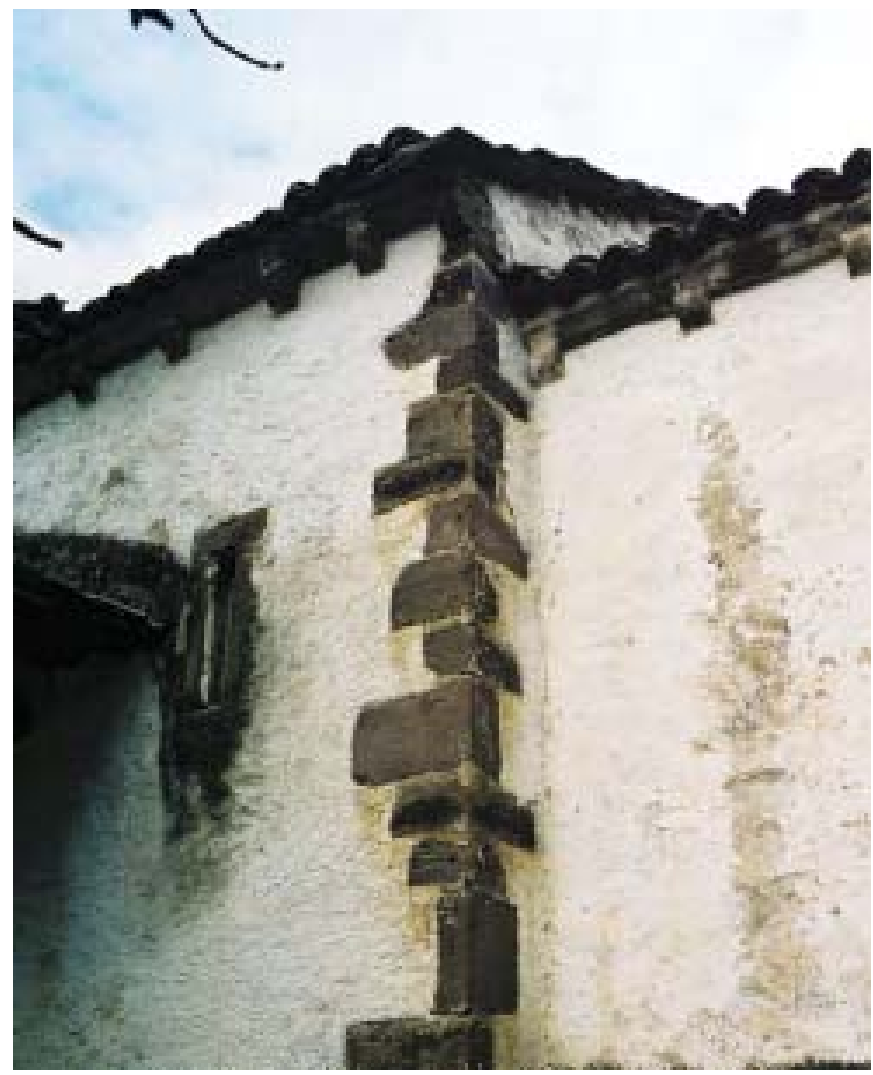

Fig. 4. San Vicente de Naviegu, siglo XIII. El entronque entre la nave y el tramo recto del presbiterio se refuerza con sillares de distintas dimensiones colocados alternado la disposición a soga y a tizón, como elemento de refuerzo estructural del edificio. El aparejo de la construcción es mampostería de caliza enripiada la iglesia de Castañéu-, presente en construcciones como San Mamés de Tebongu, Santa María de Carceda, Santa María de L.lumés, San Pedru de Bimeda, San Vicente de Naviegu (fig. 4), Santa María de Xedrez y Santa María de Monasteriu d'Ermu (fig. 5), presentando algunos edificios trabajos de cantería en los lugares estructuralmente importantes del edificio, como ocurre en la iglesia de Naviegu.

- Mampostería enripiada con hiladas de pizarra, apenas sin retocar, con los trabajos de cantería en los vanos, presente en iglesias como San Martín de Sierra, Santa María de Xarcel.lei, San Vicente de Vil.latexil (fig. 6), San Acisclo de Piñera, Santa María de Vil.lacibrán (fig. 7), San Salvador de Cibuchu y San Salvador de Berguñu.

El ambiente técnico que existe en el valle en el siglo XIII es muy similar, las obras son ejecutadas por albañiles restringiéndose los trabajos de cantería a elementos muy concretos dentro de las edificaciones; las diferencias que podemos encontrar entre los valles que confluyen en el Narcea es la utilización de distinto tipo de material: la caliza o la pizarra.

Esta homogeneidad que presenta el Alto Narcea contrasta con la ejecución en sillería del cercano monasterio de San Miguel de Bárzana (fig. 8), en el municipio de Tinéu: a falta de una detenida lectura de paramentos, se constata la existencia de una ventana geminada de arquillos de herradura colocada en la parte alta del hastial que pertenecería a la primitiva fábrica, así como una lauda del año 1003. En

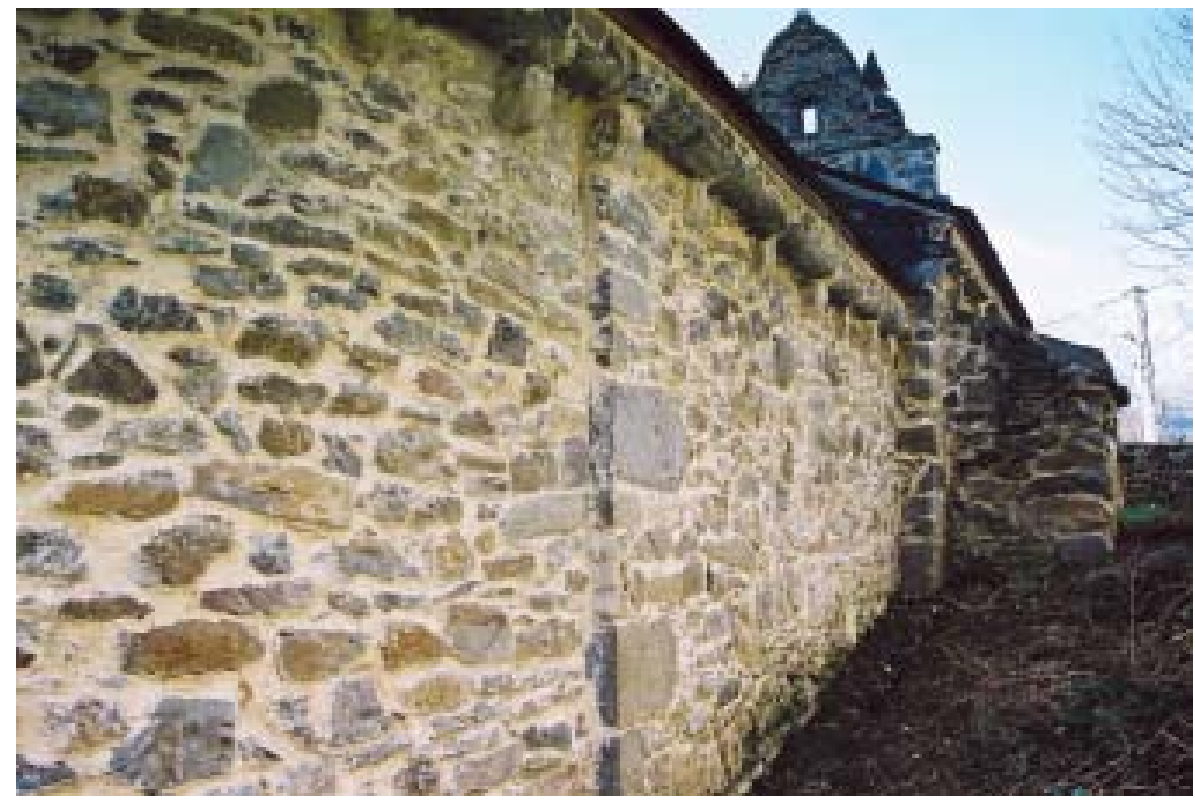

Fig. 5. Santa María de Monasteriu d'Ermu, siglo XIII. Paramento de mampostería de caliza enripiada con presencia de elementos de mayor envergadura y retocados en la zona de unión de la nave con el ábside, pero sin que podamos considerarlos trabajos realizados por un maestro cantero propiamente dicho 


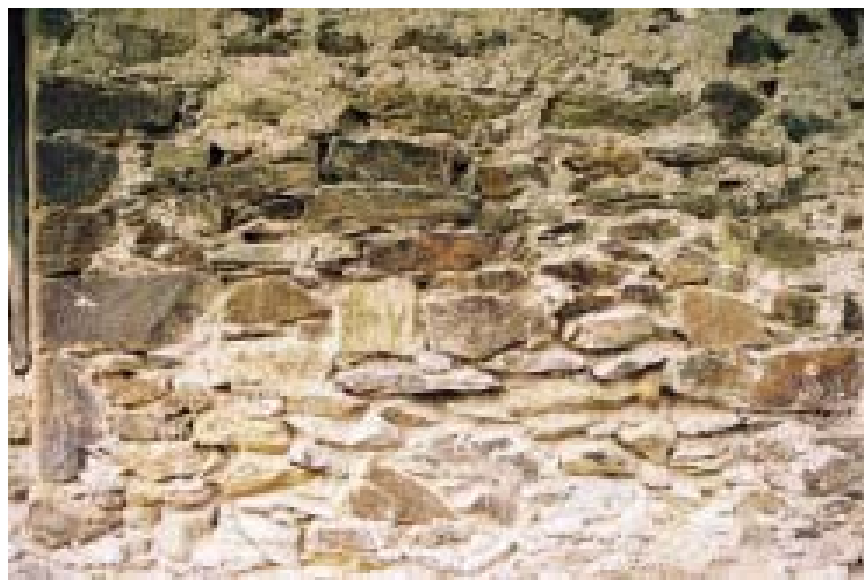

Fig. 6. San Vicente de Vil.latexil. Siglo XIII. Paramento de mampostería enripiada de pizarra que apenas forma hiladas rústicas, colocándose las lajas de pizarra sin apenas retoques, aprovechando su propio corte. Los huecos se rellenan con esquirlas de pizarra recubiertas de mortero por todos los lados. En el entronque de la nave con el presbiterio se utilizan lajas de mayor envergadura, apenas retocadas a martillo para facilitar la superposición de las hiladas

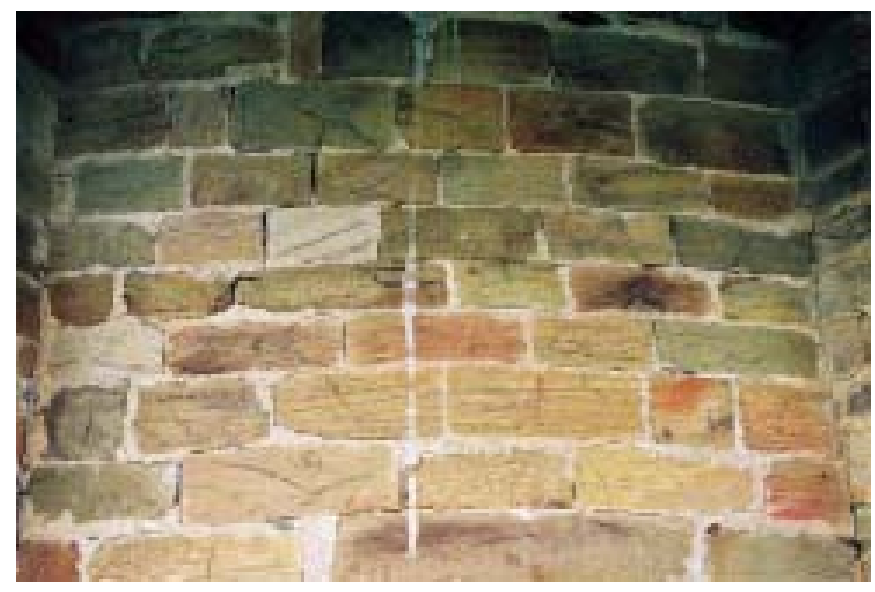

Fig. 8. San Miguel de Bárzana. Siglo xII. Presenta distintas técnicas constructivas que podrían datar de períodos cronológicos distintos. La cabecera está realizada en sillares de arenisca bien escuadrados, de pequeñas dimensiones, en los que apenas se aprecian las maestras que caracterizan el trabajo de sillería y con un acabado de las superficies realizado con azuela

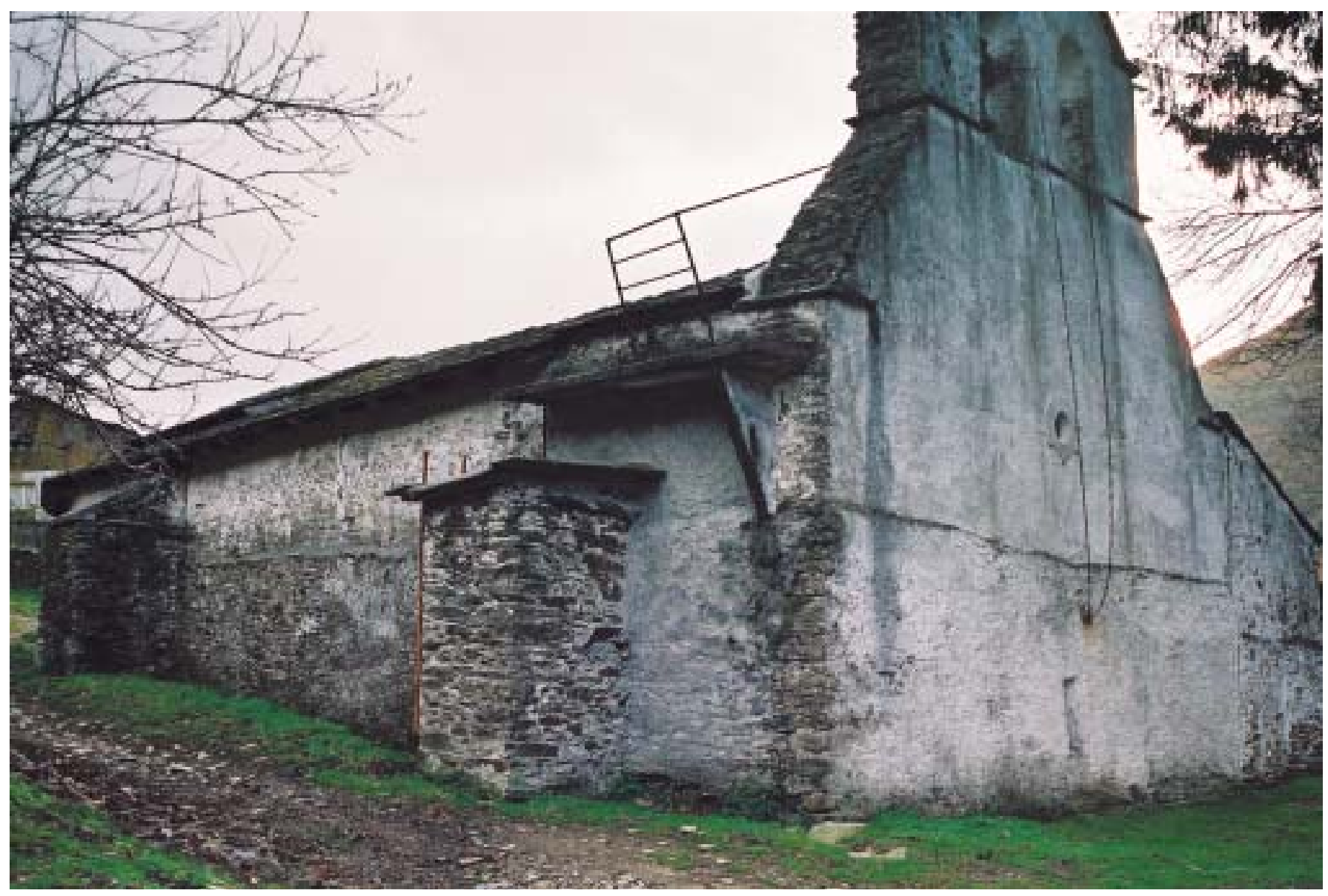

Fig. 7. Santa María de Vil.lacibrán. Siglo xill. Construcción realizada con mampostería de pizarra 
los muros de la nave la fábrica es de mampostería enripiada, utilizando diversos materiales, especialmente pizarra y caliza y construyéndose la cabecera en sillería. La utilización de la mampostería y la sillería responde a dos momentos cronológicos distintos para los que, desafortunadamente, no poseemos indicadores cronológicos que permitan atribuirles una fecha.

Todos los monasterios mencionados, en los siglos XII y XIII están incorporados al patrimonio del monasterio de Courias que, tras su fundación en el año 1044 por los condes Piniolo y Aldonza, se convirtió en el mayor poder feudal del occidente de Asturias y en el centro receptor de las donaciones de la aristocracia - la fábrica del edificio actual data del siglo XVI-. Las propiedades de estos centros se incorporan a los bienes del monasterio y son administrados por el mismo y, posiblemente, cuando se realizan las obras de fábrica que se conservan en la actualidad, la financiación de las mismas corre a cargo directo del monasterio de Courias, empleándose la mano de obra local para levantar las mamposterías de los edificios y la mano de obra cualificada de los maestros canteros para elementos muy concretos dentro de la edificación.

Distinta evolución sufrió el monasterio de Bárzana, fundado en Tinéu en el siglo X por los antepasados de la familia del Conde Piniolo, cuyas propiedades, que constituían un volumen considerable, pasaron íntegramente al patrimonio de Courias en el momento de la fundación de este último por parte de los condes Piniolo y Aldonza; sin embargo, mantuvo una fuerte influencia social en su entorno ya que a lo largo de los siglos XI y XII sigue recibiendo donaciones $y$, a pesar de depender de Courias y de entregar el tercio de sus rendimientos económicos al mismo, mantuvo su prestigio como centro espiritual y económico en su entono y su independencia administrativa (TORRENTE FERNÁNDEZ, 2000: 97). Es esta importancia como núcleo receptor de rentas lo que le permite la financiación de una construcción como la que aún se conserva en la que la mano de obra especializada de los maestros canteros prima por encima de las técnicas de albañil empleadas en los otros edificios dependientes de Courias.

\section{Bibliografía}

Alonso Álvarez R., 1993-1994, La Colegiata de San Pedro de Teverga. La "imagen medieval" de un edificio reformado, Asturiensia Medievalia, 7, pp. 225-242.

Argüello Menéndez J.J., 1996, Artesanos e industria artesanal del país asturiano en la Edad Media, Universidad de Oviedo, tesis doctoral inédita.

Arias PÁramo L., 1993, Prerrománico Asturiano. El arte de la Monarquía Asturiana, Gijón.

AzKarate Garai-Olaun A., 1995, Aportaciones al debate sobre arquitectura prerrománica peninsular: la iglesia de San Román de Tobillas (Álava), Archivo Español de Arqueología, 68, pp. 189-214.

CABALLERo Zoreda L., 1994-1995, Un canal de transmisión de lo clásico en la Alta Edad Media española. Arquitectura y escultura de influjo Omeya en la Península Ibérica entre mediados del siglo VIII e inicios del X, Al-Qantara, XV, pp. 321-348; XVI, pp. 107-124.

Caballero Zoreda L. (1999), Paleocristiano y prerrománico. Continuidad e innovación en la arquitectura cristiana hispánica, El Cristianismo. Aspectos Históricos de su origen y difusión en Hispania, Revisiones de Historia Antigua III, Veleia, Anejos —en prensa-.

Diego Santos F.: Inscripciones medievales de Asturias, Oviedo, 1993.

Fernández Mier M, Quirós CAstillo, J. A., 1999, La evolución de las técnicas constructivas en Asturias en la Edad Media, $V$ Congreso de Arqueología Medieval Española, vol. 1,Valladolid, pp. 371-382.

FERNÁNDEZ MIER M, 2002, Territorialidad y poblamiento: el occidente de Asturias en época de la Monarquía Asturiana, La Época de la Monarquia Asturiana, Actas del Simposio Celebrado en Covadonga (8-10 de octubre de 2001), Oviedo, pp. 43-61.

FERNÁNDEZ OCHOA C., 1997, La muralla romana de Gijón (Asturias), Gijón.

Floriano Cumbreño A.C., 1950, El Libro Registro de Corias, Oviedo.

García de Castro C., 1995, Arqueología cristiana de la Alta Edad Media en Asturias, Oviedo

GarCía de CASTRO C., Ríos GonZÁlez S., 1996, Introducción a la arquitectura en Asturias en los siglos VIII-IX, Gijón.

García de Cotazar J.A., 1994, Crecimiento económico y sintomas de transformación en las estructuras de la sociedad y del hábitat en el reino de Alfonso III de Asturias, La época de Alfonso III y San Salvador de Valdedios, Oviedo, 27-53.

García LarRagueta S., 1962, Colección de documentos de la Catedral de Oviedo, Oviedo.

GómeZ Moreno M., 1919, Iglesias mozárabes. Arte Español de los siglos $I X$ a XI, Centro de Estudios Históricos, Madrid (Patronato de la Alhambra, Granada, 1975).

LORING GARCíA I., 1987, Nobleza e iglesia propias en la Cantabria Altomedieval, Studia Histórica, V, pp. 89-120.

MANnONi T., 1988, Archeologia della produzione, en Francovich R., Parenti R., (eds.), Archeologia e restuaro di monumenti, Florencia, pp. 403-420.

Quirós CASTILlo J.A., 1998, La sillería y las técnicas constructivas medievales: historia social y técnica de la producción arquitectónica, $A r$ cheologia Medievale XXV, pp. 235-246.

Ruiz De la PeÑa I., 1995, La Monarquía Asturiana (718-910), en El Reino de León en la Alta Edad Media, León. 